\title{
Abdominal wall hernia in a rural population in India-Is spectrum changing?
}

\author{
Mukesh Sangwan ${ }^{1 *}$, Vijayata Sangwan ${ }^{2}$, Mahender Garg ${ }^{1}$, Parveen Mahendirutta ${ }^{1}$, Uma Garg $^{1}$ \\ ${ }^{1}$ Deptt. of General Surgery, BPS Govt Medical College, Khanpur Kalan, Sonepat, India \\ ${ }^{2}$ Deptt. of Obst. \& Gynae, BPS Govt Medical College, Khanpur Kalan, Sonepat, India \\ Email: *mksangwan11@gmail.com, vsangwan03@gmail.com, drumamkgarg_962@yahoo.co.in, mksangwan11@gmail.com, \\ drumamkgarg_962@yahoo.co.in
}

Received 18 May 2013; revised 16 June 2013; accepted 30 June 2013

Copyright (c) 2013 Mukesh Sangwan et al. This is an open access article distributed under the Creative Commons Attribution License, which permits unrestricted use, distribution, and reproduction in any medium, provided the original work is properly cited.

\begin{abstract}
Hernia is a common word that most surgeons are familiar with. A retrospective study was planned to analyse the spectrum of abdominal wall hernias in a rural population in India. Majority of the patients were of 40 - 70 yrs. Male to female ratio was 7:1. Incidence of groin hernias showed an increasing trend with ad- vancing age. Out of total 320 cases, inguinal hernias were predominating in $77.81 \%$ cases. Ventral hernias were present in about $18 \%$ cases. However, femoral hernias were rare. We concluded that spectrum of abdominal wall hernias is almost the same all over the globe despite having differences in their socioeconomic and educational status.
\end{abstract}

Keywords: Abdominal Wall Hernia; Inguinal Hernia; Ventral Hernia

\section{INTRODUCTION}

Hernia is derived from a latin word meaning "a rupture". Abdominal wall hernias are frequently encountered in surgical practice accounting for $15 \%$ - $18 \%$ of all surgical procedures $[1,2]$. Worldwide, more than 20 millions hernias are operated per year [3]. More than 750,000 hernias in USA and approximately 125,000 hernias in United Kingdom are operated per year [4]. The incidence of abdominal wall hernia in different countries varies from 100 - 300/100000 per year [3]. We could not find Indian data despite literature and medline search. Approximately $75 \%$ cases of all abdominal wall hernias [5] belong to groin. Lifetime risk of developing inguinal hernia is $15 \%-27 \%$ in men and $3 \%$ in women [6]. Although males are affected more commonly (7:1), the incidence of femoral hernia is four times higher in fe-

"Corresponding author. males [7]. The incidence of hernia increases with advancingage. Indirect hernia is twice as common as direct hernia. Inguinal hernias are more common on right side. In recurrent inguinal hernia, direct type is twice as common as indirect [1]. The incidence of recurrence is less than $1 \%$ in Lichtenstein repair [7]. The incidence of congenital hernias is more common in low birth weight babies. Incisional hernias are more common in males [8]. Midline ventral hernias are the next common variety of abdominal wall hernia after inguinal hernia. According to their locations, these are further classified into umbilical, paraumblical and epigastric hernia. Traumatic and obturator hernias are rare [9].

\section{MATERIALS AND METHODS}

A retrospective study of 320 cases of abdominal wall hernias operated at BPS Govt Med College for Women khanpur kalan sonepat India from February 2012 to February 2013. The data was collected from their casesheets available in hospital. The data was compiled and analysed.

\section{RESULTS}

Over a period of one year, 320 cases of abdominal wall hernias were operated at our institute which constituted $22 \%$ of the operative workload of the general surgery department. Age varies from 3 months to 82 years with an increasing incidence with age (Table 1).

The male to female ratio is 7:1 as shown in Table 2 . Groin and incisional hernias are more common in men but ventral hernias showed a female dominance (Table 2). Inguinal hernia was commonest variety followed by paraumblical, umbilical, epigastric, incisional, obturator, traumatic and femoral hernia in decreasing order depicted in Table 3.

The incidence of inguinal and incisional hernias was 
low in our study as compared to western countries [8] but ventral hernias showed a opposite trend in our study (Table 4).

Prostatism was commonest associated illness followed by hypertension and respiratory diseases (Table 5). Seroma formation was commonest complication in post operative period followed by wound infection and pyrexia despite routine use of antibiotics in all cases shown in Table 6.

Table 1. Age distribution.

\begin{tabular}{ccc}
\hline Age group (yrs) & No. of patients & \% of total patients \\
\hline $0-9$ & 31 & 9.68 \\
$10-19$ & 23 & 7.18 \\
$20-29$ & 31 & 9.68 \\
$30-39$ & 35 & 10.93 \\
$40-49$ & 56 & 17.50 \\
$50-59$ & 61 & 19.06 \\
$60-69$ & 61 & 19.06 \\
$70-79$ & 21 & 6.56 \\
80 or more & 2 & 0.62 \\
\hline
\end{tabular}

Table 2. Sex distribution.

\begin{tabular}{cccc}
\hline Type of hernia & Males & Females & Ratio (M/F) \\
\hline Inguinal & 246 & 3 & $82: 1$ \\
Umblical & 12 & 7 & $1.71: 1$ \\
Paraumblical & 11 & 18 & $1: 1.63$ \\
Epigastric & 3 & 8 & $1: 2.66$ \\
Incisional & 8 & 2 & $4: 1$ \\
Traumatic & - & 1 & - \\
Obturator & - & 1 & - \\
Total & 280 & 40 & $7: 1$ \\
\hline
\end{tabular}

Table 3. Typewise distribution of abdominal wall hernia.

\begin{tabular}{ccc}
\hline Type of hernia & No. of patients & \% of total patients \\
\hline Right-direct & 67 & 20.93 \\
Right-indirect & 72 & 22.50 \\
Left-direct & 37 & 11.56 \\
Left-indirect & 53 & 16.56 \\
Bilateral inguinal & 20 & 6.25 \\
Umblical & 19 & 5.93 \\
Paraumblical & 29 & 9.06 \\
Epigastric & 11 & 3.43 \\
Incisional & 10 & 3.12 \\
Obturator & 1 & 0.31 \\
Traumatic & 1 & 0.31 \\
\hline
\end{tabular}

Table 4. Epidemiology of abdominal wall hernias in various countries.

\begin{tabular}{ccccc}
\hline Type of hernia & USA & UK $^{\mathbf{8}}$ & Pakistan & Present study \\
\hline Inguinal & 88 & 82.05 & 76.35 & 77.81 \\
Paraumblical & 3 & 3 & 12.38 & 9.06 \\
Umblical & - & - & 3.95 & 5.93 \\
Incisional & 10 & 6.50 & 2.7 & 3.12 \\
\hline
\end{tabular}

Table 5. Comorbid illnesses.

\begin{tabular}{ccc}
\hline Diseases & No. of patients & \% of total patients \\
\hline Diabetes mellitus & 10 & 3.12 \\
Hypertension & 35 & 10.93 \\
Prostatism & 51 & 15.93 \\
Respiratory diseases & 13 & 4.06 \\
\hline
\end{tabular}

Table 6. Postoperative complications.

\begin{tabular}{ccc}
\hline Complication & No. of patients & \% of total patients \\
\hline Wound infection & 10 & 3.12 \\
Seroma & 17 & 5.31 \\
Hematoma & 2 & 0.62 \\
Pyrexia & 7 & 2.18 \\
\hline
\end{tabular}

\section{DISCUSSION}

Being a commonly performed general surgical operation, abdominal wall hernia comprises a significant proportion of total surgical work load in most of the centres. Although it has been reported to constitute $15 \%$ - $18 \%$ of total surgical operations but a slightly higher prevalence of $22 \%$ in present study may be due to rural population having agriculture as main profession. Smoking, old age and neglected urinary obstructive symptoms may be the other contributory factors. Inguinal hernia constituted $77.81 \%$ of total abdominal wall hernias which is in accordance with literature. Inguinal hernia is twice more common on right side due to late descend of right testis and more frequent failure of closure of right processus vaginalis $[9,10]$. In present study the ratio of right to left is $1.45: 1$. The incidence of direct and indirect hernia is almost equal however, indirect hernias are more common below 50 years of age than direct but direct hernia predominates as the age advances which may be attributed to physiological wear and tear of fibromuscular tissues, prostatic hypertrophy and comorbid illnesses. The incidence of abdominal wall hernia increases with aging as revealed in present study also except for first decade of life which might be due to presentation of congenital hernias in this decade. The youngest patient was only 3 months old while oldest was of age 82 years. The median age was 42 years which is more as compared to western countries but less as compared to African countries [1,9]. 
It may be depending on awareness and education of the population and other limiting factors like negligence being the only earning member of the family and low socioeconomic status.

Males outnumbered females by a ratio of $7: 1$ which is more as compared to 5:1 of US [11]. It may be do to the trend that males are more involved insternous work in agriculture while females are predominantly entitled the household works. This trend holds true in all abdominal wall hernias except paraumblical and epigastric hernias where females are predominant. In females, paraumblical hernia is the commonest type followed by epigastric and umbilical hernias which is in contrary to literature where umbilical hernia followed by incisional hernia are in trends [12]. It may be due to high fertility rate and malnutrition. A low prevalence of congenital umbilical hernia in females may be another contributory factor. Unexpectedly high incidence of epigastric hernia in females than males in our study is again in contrary to the literature explainable by above mentioned factors. Surprisingly low incidence of groin hernias in our female population as compared to literature could not be reflecting the true incidence due to underreporting. The male to female ratio of inguinal hernia is very high in our study ascompared to literature which may be due to casual attitude of rural females to this disease leading to underreporting of the disease.

The order of hernia frequency in our study in decreasing order is inguinal, paraumblical, umbilical, epigastric, incisional, obturator and femoral hernia which obviously differs from literature mentioning the frequency as: inguinal, femoral, umbilical and others. The incidence of femoral hernia is very low in our study as compared to literature where it comes as third commonest type of hernia. It may be due to some racial factors as wider pelvis has been thought to be an important factor as an etiological agent of femoral hernia. Bilateral inguinal hernias were present in 20 cases out of which 32 were direct hernias.

Umbilicalhernias are also not uncommon and have been documented as an acquired disease in more than 90\% cases [13]. Multiparity, obesity, malnutrition and raised intra abdominal pressure have been assigned as predisposing factors. In present study also they constitute approximately $18 \%$ of the total cases which is in concordance with other studies.

Incisional hernia was noticed in approximately 3\% of the cases which is significantly lower than USA and UK where it has been reported in $6 \%$ - $10 \%$ of cases but in accordance with African literature [8,9]. It may be due to underreporting of these cases as our population is relatively less disease conscious.

Abdominal wall hernias have been reported more prevalent in low socioeconomic status which holds true for our rural population also [14]. Concomittent medical disease has been reported as having role in its etiology as well as in increasing morbidity and mortility in postoperative period. Symptoms of prostatism were present in approximately $16 \%$ cases while hypertension and diabetes were present in approximately $11 \%$ and 5\% cases respectively.

In the past decades the complication rates of abdominal wall hernias have drastically improved with the use of prosthetic mesh. We have used mesh unanimously in all cases except pediatric, strangulated and small ventral hernias. No recurrence has been reported till date. Complication rate of approximately $11 \%$ has been noticed in our study which is in the range of $4 \%-12 \%$ mentioned in literature [10]. Seroma formation was commonest complication noted in approximately $5 \%$ of the cases followed by wound infection in $3 \%$ cases. Complications like irreducibility, obstruction and strangulation are decreasing reflecting awareness of population, better health facilities and improving quality. In our study only $7.5 \%$ cases were operated in emergency as compared to 35\% in Nigeria. However all complications were managed conservatively without need of mesh removal.

\section{CONCLUSION}

The spectrum of abdominal wall hernias is more or less constant throughout the world despite having differences in educational, economic and social status. Early diagnosis, easily accessable health facilities and health education are important to prevent complications.

\section{REFERENCES}

[1] Mebula, J.B. and Chalya, P.L. (2012) Surgical management of inguinal hernias at Bugando medical centre in northwestern Tanzania: Our experience in a resource-limited setting. Mebula and Chalya BMC Research, 5, 585.

[2] Primatesia, P. and Golacre, M.J. (1996) Inguinal hernia repair, incidence of elective and emergency surgery. International Journal of Epidemiology, 25, 835-839. doi:10.1093/ije/25.4.835

[3] Kingnorth, A.N. and Leblanc, K.A. (2003) Management of abdominal hernias. 3rd Edition, Edward Arnold, London.

[4] Rutkow, I.M. (2003) Demographic and socioeconomic aspects of hernia repair in United States in 2003. Surgical Clinics of North America, 83, 1045-1051. doi:10.1016/S0039-6109(03)00132-4

[5] Javid, P.J. and Brooks, D.C. (2007) Hernias. In: Zinner, M.J. and Ashley, S.W., Eds., Maingots Abdominal Operations, Vol. 1, 11th Edition, McGraw-Hill, New York, 103-139.

[6] Gulzar, M.R., Iqbal, J., Ulhaq, M.I. and Afzal, M. (2007) Darning vs Bassini repair for inguinal hernia-A prospective comparative study. Professional Medical Journal, 14, 128-133. 
[7] Fitzgibbons, R.J., Filipi, C.J. and Thomas, H.Q. (2005) Inguinal hernia. In: Brunicardi, F.C., Andersen, D.K., Billiar, T.R., Dunn, D.L., Hunter, J.G. and Pollock, R.E., Eds., Schwartz's Principles of Surgery, 8th Edition, McGrawHill, New York.

[8] Sultan, B., Qureshi, Z. and Malik, M.A. (2009) Frequency of external hernias in Ayub teaching hospital Abbottabad. Journal of Ayub Medical College Abbottabad, 21, 57-58.

[9] Garba, E.S. (2000) The pattern of adult external abdominal hernias in Zaria. Nigerian Journal of Surgical Research, 2, 12-15.

[10] Mbah, N. (2007) Morbidity and mortality associated with inguinal hernia in northwestern Nigeria. West African Journal of Medicine, 26, 288-292.
[11] Zimmermann, L.M. and Amson, B.J. (1967) Anatomy and surgery of hernias, 2nd Edition, Willium and Wilkins, Baltimore.

[12] Russell, R.C.G., Williams, N.S. and Bulstrode, C.J.K. (2000) Bailey and love's short practice of surgery. 23rd Edition, Hodder Arnold, London.

[13] Ammar, S.A. and Ismail, T. (2008) Abdominal wall hernias in upper Egypt: A different spectrum. East and Central African Journal of Surgery, 13, 109-113.

[14] Osifo, O.D. and Amusan, T. (2010) Outcome of giant inguinosacrotal hernia repair with local lidocaineanaesthesia. Saudi Medical Journal, 31, 53-58. 